NBER WORKING PAPER SERIES

\title{
THE GENERAL EQUILIBRIUM INCIDENCE OF ENVIRONMENTAL TAXES
}

\author{
Don Fullerton \\ Garth Heutel \\ Working Paper 11311 \\ http://www.nber.org/papers/w11311
}

\author{
NATIONAL BUREAU OF ECONOMIC RESEARCH \\ 1050 Massachusetts Avenue \\ Cambridge, MA 02138 \\ May 2005
}

We are grateful for funding from the AERE, the University of Texas, the National Science Foundation Graduate Research Fellowship Program, and Japan's Economic and Social Research Institute (ESRI). For helpful suggestions, we thank John List, Gib Metcalf, Ian Parry, Kerry Smith, Chris Timmins, Rob Williams, and seminar participants at the University of Texas at Austin, the 2004 AERE Workshop in Estes Park, CO, and Camp Resources XII in Wilmington, NC. This paper is part of the NBER's research program in Public Economics. Any opinions expressed are those of the authors and not those of the AERE, UT, the NSF, ESRI, or the National Bureau of Economic Research.

(C2005 by Don Fullerton and Garth Heutel. All rights reserved. Short sections of text, not to exceed two paragraphs, may be quoted without explicit permission provided that full credit, including $(\odot)$ notice, is given to the source. 
The General Equilibrium Incidence of Environmental Taxes

Don Fullerton and Garth Heutel

NBER Working Paper No. 11311

May 2005

JEL No. H23, Q52

\begin{abstract}
We study the distributional effects of a pollution tax in general equilibrium, with general forms of substitution where pollution might be a relative complement or substitute for labor or for capital in production. We find closed form solutions for pollution, output prices, and factor prices. Various special cases help clarify the impact of differential factor intensities, substitution effects, and output effects. Intuitively, the pollution tax might place disproportionate burdens on capital if the polluting sector is capital intensive, or if labor is a better substitute for pollution than is capital; however, conditions are found where these intuitive results do not hold. We show exact conditions for the wage to rise relative to the capital return. Plausible values are then assigned to all the parameters, and we find that variations over the possible range of factor intensities have less impact than variations over the possible range of elasticities.
\end{abstract}

Don Fullerton

Department of Economics

University of Texas at Austin

Austin, TX 78712

and NBER

dfullert@eco.utexas.edu

Garth Heutel

Department of Economics

University of Texas at Austin

Austin, TX 78712

heutel@eco.utexas.edu 
Policy makers need to know the distributional effects of environmental taxes. Previous studies that find environmental taxes to be regressive have focused on the uses side of income, that is, how low-income consumers use a relatively high fraction of their income to buy gasoline, electricity, and other products that involve burning fossil fuel. Yet these studies ignore the sources side of income. Environmental policies can have important effects on firms' demands for capital and labor inputs, which can impact the returns to owners of capital and labor in a general equilibrium setting.

The literature in public economics contains much work on general equilibrium tax incidence, but the literature on environmental taxation has focused mostly on efficiency effects. As reviewed below, neither literature yet has studied the general equilibrium incidence of a pollution tax in a model with general forms of substitution. Environmental tax incidence has been studied only in partial equilibrium models, in computational general equilibrium (CGE) models, or in analytical general equilibrium models with limited forms of substitution. This paper provides a theoretical general equilibrium model of the incidence of an environmental tax that allows for differential factor intensities and fully general forms of substitution among inputs of labor, capital, and pollution. We show incidence on the sources side as well as the uses side.

Many empirical studies provide partial equilibrium analyses of the incidence of an environmental tax. For example, Robison (1985) examines the distribution of the costs of pollution abatement from 1973-1977 and finds regressive burdens equal to $1.09 \%$ of the income of the lowest income class and only $0.22 \%$ of income for the highest income class. Using CGE models, Mayeres (1998) and Metcalf (1999) look at various ways to return the revenue from an environmental tax, showing that these distributional effects can more than offset the incidence of the environmental tax itself. Morgenstern et al (2002) discuss four CGE studies that examine various distributional effects of carbon policy, but none derive analytical results and none show effects on factor prices. ${ }^{1}$

Previous theoretical work on environmental tax incidence by Rapanos (1992, 1995) models pollution in one sector as a negative externality that affects production in the other sector. The model is somewhat restrictive in two respects. First, the externality has a specific effect on production in the other sector, which affects incidence. Second, Rapanos assumes that that pollution bears a fixed relation to output (or to capital input) of the polluting sector, so a tax on pollution has the same incidence as a tax on output (or on capital input). In contrast, this paper models pollution as a variable input to the dirty sector's production function. In response to any price change, the producer can change the mix of labor, capital, and pollution. In particular, pollution can be a relative complement or substitute for labor or capital, so that a pollution tax can change the relative demands for those other two factors and affect their relative returns.

Bovenberg and Goulder (1997) examine the efficiency costs of a revenue-neutral environmental tax swap and also solve for the change in the wage rate. Their analytical model considers variable pollution, but the production function has a single elasticity of substitution among the three inputs (capital, labor, and pollution). This formulation does not allow for relative complementarity of inputs in production, a possibility that drives

\footnotetext{
${ }^{1}$ Also, West and Williams (2002) use micro data to model demand equations and empirically estimate the distribution of burdens of environmental policy. Parry (2004) examines the distribution of the scarcity rents created by grandfathered emissions permits. In a model with unemployment, Wagner (2005) shows that an emissions tax can help labor to the extent that it stimulates employment in the abatement sector.
} 
significant results below. ${ }^{2}$ Chua (2003) presents a model where pollution is a scalar multiple of output, but it can be lowered by paying an abatement sector that also uses labor and capital. Because the effect on factor prices depends on use of factors in the abatement sector, this model effectively makes some restrictions on the ways that firms can substitute out of pollution and into other factors such as labor and capital. ${ }^{3}$

Our model does not fix pollution as a scalar multiple of output, nor of capital, nor does it posit a third sector for abatement. Rather, pollution is modeled as an input along with capital and labor. Minimal restrictions are placed on that production function, so that the model is free to consider that any pair of inputs may be complements or substitutes. We then solve the model in the style of Harberger (1962) to find closed form solutions for the general equilibrium responses to a change in the tax on pollution, in the presence of other taxes. The model allows for analyses of a wide variety of policies.

Some of the general results are complex and ambiguous, so special cases are used to provide intuition. In the case where the two sectors have equal capital-labor ratios, for example, an increase in the pollution tax unambiguously raises the price of the dirty good relative to the clean good. We then show specific conditions for the pollution tax to raise or lower the equilibrium wage-rental ratio. Most of these results are intuitive, but some are surprising. One might think that the pollution tax raises the relative return of the factor that is the better substitute for pollution, but a surprising result is that the opposite holds if labor and capital are highly complementary. Then the better substitute for pollution bears proportionally more of the burden of the pollution tax.

Another special case allows for differential factor intensities but abstracts from differential substitutability for pollution. Normally the pollution tax then lowers the relative return of the factor that is intensively used in the dirty sector, but a second surprising result is that the opposite holds if the dirty sector can substitute among its inputs more easily than consumers can substitute between outputs. Then the factor that is intensively used in the dirty sector bears proportionately less of the burden of the pollution tax. A final unusual result is that even though the tax withdraws resources from the private economy, one of the factors could actually gain in real terms. We provide explanations for these counterintuitive results.

The next section presents the model and uses it to derive a system of equations. Then the second section offers a general solution and simplifies it in several cases to interpret the results. While the main contributions here are the propositions about incidence, the third section proceeds to insert plausible values for parameters and to calculate examples of the incidence of environmental policy. It shows that varying the factor intensities over their plausible range has less impact on incidence than varying substitution elasticities over their plausible range. The fourth section thus concludes that it is important next to estimate substitution elasticities. This concluding section also

\footnotetext{
2 DeMooij and Bovenberg (1998) allow for complementarity of inputs, and they derive the change in the wage rate, but their model is primarily used to examine the efficiency of revenue-neutral tax swaps. To the extent that they examine incidence, their results are somewhat limited by the fact that capital either has an exogenous price or is supplied inelastically in the polluting industry.

${ }^{3}$ McAusland (2003) develops a theoretical model to examine the role of inequality in endogenous environmental policy choice, and Aidt (1998) explores how heterogeneous agents may influence environmental policy through political processes. While both models are concerned with inequality, neither is strictly an examination of the incidence of environmental policy. Likewise, Bovenberg, Goulder and Gurney (2005) consider the efficiency costs of environmental taxation under a distributional constraint.
} 
notes caveats. Indeed, our model could be extended in many of the same ways that the original Harberger (1962) model was extended over the following decades. ${ }^{4}$

\section{Model}

The simple model developed here is used to solve for all changes in prices and quantities that result from an exogenous change in the pollution tax. No government revenue neutrality is imposed, however, so an increase in one tax need not be offset by a decrease in another tax. Instead, as in Harberger (1962) and others, the government is assumed to use the increased revenue to purchase the two private goods in the same proportion as do households. Thus, the transfer from the private sector to the public sector has no effect on relative demands or on prices. We consider a competitive twosector economy using two factors of production, capital and labor. Both factors are mobile and can be used by either sector. A third variable input is pollution, $Z$, necessary to produce one of the outputs. The constant returns to scale production functions are:

$$
\begin{gathered}
X=X\left(K_{X}, L_{X}\right) \\
Y=Y\left(K_{Y}, L_{Y}, Z\right),
\end{gathered}
$$

where $X$ is the "clean" good, $Y$ is the "dirty" good, $K_{X}$ and $K_{Y}$ are the capital inputs in each sector, and $L_{X}$ and $L_{Y}$ are the labor inputs in each sector. ${ }^{5}$ The resource constraints are:

$$
\begin{gathered}
K_{X}+K_{Y}=\bar{K}, \\
L_{X}+L_{Y}=\bar{L},
\end{gathered}
$$

where $\bar{K}$ and $\bar{L}$ are the fixed total amounts of capital and labor in the economy. Totally differentiating these two constraints yields:

$$
\begin{gathered}
\hat{K}_{X} \lambda_{K X}+\hat{K}_{Y} \lambda_{K Y}=0, \\
\hat{L}_{X} \lambda_{L X}+\hat{L}_{Y} \lambda_{L Y}=0 .
\end{gathered}
$$

where a hat denotes a proportional change $\left(\hat{K}_{X} \equiv d K_{X} / K_{X}\right)$ and $\lambda_{i j}$ denotes sector $j$ 's share of factor $i$ (e.g. $\lambda_{K X} \equiv K_{X} / \bar{K}$ ). Notice that $Z$ has no equivalent resource constraint. The amount of $Z$ used by the dirty sector depends only on that sector's decision, with no upper limit. To ensure finite use of pollution in the initial equilibrium, we start with a pre-existing positive tax on pollution. ${ }^{6}$

Producers of $X$ can substitute between labor and capital in response to changes in the gross-of-tax factor prices they face, $p_{L}$ and $p_{K}$, according to their elasticity of substitution in production $\sigma_{X}$. The definition of $\sigma_{X}$ is differentiated and rearranged to obtain the firm's response to a change in prices, $\hat{K}_{X}-\hat{L}_{X}=\sigma_{X}\left(\hat{p}_{L}-\hat{p}_{K}\right)$, where $\sigma_{X}$ is defined to be positive. The firm's cost of capital can be written as $p_{K}=r\left(1+\tau_{K}\right)$, where

\footnotetext{
${ }^{4}$ See McLure (1975) and Fullerton and Metcalf (2002) for summaries of these extensions.

${ }^{5}$ As is typical in environmental models, the second production function includes pollution as an input. This is simply a rearrangement of a production function where both $Y$ and $Z$ are functions of $K_{Y}$ and $L_{Y}$.

${ }^{6}$ This problem could also be solved by introducing a private cost of pollution, separate from the tax (see Fullerton and Metcalf, 2001). Here, we merely assume that the initial tax is positive and hence examine a change in the pollution tax rate rather than the introduction of a pollution tax.
} 
$r$ is the net return to capital and $\tau_{K}$ is the ad valorem rate of tax on capital. Similarly, $p_{L}=w\left(1+\tau_{L}\right)$, where $w$ is the net wage and $\tau_{L}$ is the labor tax. Differentiating these equations in the same manner yields $\hat{p}_{K}=\hat{r}+\hat{\tau}_{K}$ and $\hat{p}_{L}=\hat{w}+\hat{\tau}_{L}$, where all variables are defined analogously, except that $\hat{\tau}_{K} \equiv \frac{d \tau_{K}}{1+\tau_{K}}$ and $\hat{\tau}_{L} \equiv \frac{d \tau_{L}}{1+\tau_{L}}$. Then substitution into the $\sigma_{X}$ expression yields the production decision:

$$
\hat{K}_{X}-\hat{L}_{X}=\sigma_{X}\left(\hat{w}+\hat{\tau}_{L}-\hat{r}-\hat{\tau}_{K}\right) .
$$

The choice of inputs in sector $Y$ is more complicated, since it has three inputs. First, note that firms face no market price for pollution except for a tax, so $p_{Z}=\tau_{Z}$ (and $\hat{p}_{Z}=\hat{\tau}_{Z}$, where $\left.\hat{\tau}_{Z}=d \tau_{Z} / \tau_{Z}\right)$. This tax per unit of pollution is a specific tax rather than an ad valorem tax. We then follow Mieszkowski (1972) in modeling this choice of inputs. As shown in the Appendix, the resulting equations are:

$$
\begin{aligned}
& \hat{K}_{Y}-\hat{Z}=\theta_{Y K}\left(e_{K K}-e_{Z K}\right)\left(\hat{r}+\hat{\tau}_{K}\right)+\theta_{Y L}\left(e_{K L}-e_{Z L}\right)\left(\hat{w}+\hat{\tau}_{L}\right)+\theta_{Y Z}\left(e_{K Z}-e_{Z Z}\right) \hat{\tau}_{Z} \\
& \hat{L}_{Y}-\hat{Z}=\theta_{Y K}\left(e_{L K}-e_{Z K}\right)\left(\hat{r}+\hat{\tau}_{K}\right)+\theta_{Y L}\left(e_{L L}-e_{Z L}\right)\left(\hat{w}+\hat{\tau}_{L}\right)+\theta_{Y Z}\left(e_{L Z}-e_{Z Z}\right) \hat{\tau}_{Z},
\end{aligned}
$$

where $\theta_{Y j}$ is the share of factor $j$ in sector $Y$ 's production, and $e_{i j}$ is the Allen elasticity of substitution between inputs $i$ and $j$ (Allen 1938). This elasticity is positive when the two inputs are substitutes and is negative when they are complements. Note that $e_{i j}=e_{j i}$, that $e_{i i}<0$, and that at least two of the three cross-price elasticities must be positive.

In a sense, we could avoid saying that pollution is an "input" to the production function $Y=Y\left(K_{Y}, L_{Y}, Z\right)$ and instead just specify equations (4)-(5). In that case, the Allen elasticities of substitution are a direct way to model the choices of firms. A higher tax on pollution leads firms to pollute less $\left(e_{Z Z}<0\right)$, holding output constant, and it may raise or lower use of labor or capital in ways that depend on the signs and magnitudes of $e_{L Z}$ and $e_{K Z}$. The point is just that these reactions affect the incidence of the tax.

The Appendix also shows how assumptions of perfect competition and constant returns to scale are used to derive the following two equations:

$$
\begin{gathered}
\hat{p}_{X}+\hat{X}=\theta_{X K}\left(\hat{r}+\hat{\tau}_{K}+\hat{K}_{X}\right)+\theta_{X L}\left(\hat{w}+\hat{\tau}_{L}+\hat{L}_{X}\right), \\
\hat{p}_{Y}+\hat{Y}=\theta_{Y K}\left(\hat{r}+\hat{\tau}_{K}+\hat{K}_{Y}\right)+\theta_{Y L}\left(\hat{w}+\hat{\tau}_{L}+\hat{L}_{Y}\right)+\theta_{Y Z}\left(\hat{Z}+\hat{\tau}_{Z}\right),
\end{gathered}
$$

where $p_{X}$ and $p_{Y}$ are output prices, $\theta_{X K} \equiv \frac{r\left(1+\tau_{K}\right) K_{X}}{p_{X} X}$ is the share of sales revenue of sector $X$ that is paid to capital, and other shares are defined similarly $\left(\theta_{X L}, \theta_{Y K}\right.$, and $\left.\theta_{Y L}\right)$. Note that $\theta_{Y Z} \equiv \frac{\tau_{Z} Z}{p_{Y} Y}$ is the share of revenue of sector $Y$ that is paid for pollution, through taxes. Also note that $\theta_{X K}+\theta_{X L}=1$ and $\theta_{Y K}+\theta_{Y L}+\theta_{Y Z}=1$.

Totally differentiate each sector's production function and substitute in the conditions from the perfect competition assumption shown in the Appendix to yield:

$$
\begin{gathered}
\hat{X}=\theta_{X K} \hat{K}_{X}+\theta_{X L} \hat{L}_{X} \cdot \\
\hat{Y}=\theta_{Y K} \hat{K}_{Y}+\theta_{Y L} \hat{L}_{Y}+\theta_{Y Z} \hat{Z} .
\end{gathered}
$$


Finally, consumer preferences for the two goods can be modeled using $\sigma_{u}$, the elasticity of substitution between goods $X$ and $Y$ in utility. ${ }^{7}$ Differentiate the definition of $\sigma_{u}$ to get the equation for consumer demand response to a change in prices:

$$
\hat{X}-\hat{Y}=\sigma_{u}\left(\hat{p}_{Y}+\hat{\tau}_{Y}-\hat{p}_{X}-\hat{\tau}_{X}\right),
$$

where $\hat{\tau}_{X} \equiv \frac{d \tau_{X}}{1+\tau_{X}}$ is the change in the tax on $X$ (and similarly for $\tau_{Y}$ ).

Equations (1) - (10) are ten equations in eleven unknowns $\left(\hat{K}_{X}, \hat{K}_{Y}, \hat{L}_{X}, \hat{L}_{Y}\right.$, $\left.\hat{w}, \hat{r}, \hat{p}_{X}, \hat{X}, \hat{p}_{Y}, \hat{Y}, \hat{Z}\right)$. Good $X$ is chosen as numeraire, so $\hat{p}_{X}=0$, and this system of ten equations provides solutions to all ten unknown endogenous changes as functions of parameters and of an exogenous change in any of the tax rates. ${ }^{8}$ This paper focuses on the effects of an exogenous increase in the pollution $\operatorname{tax}\left(\hat{\tau}_{Z}>0\right)$.

Our primary purpose is to solve for incidence results, that is, the effects on output prices and factor prices. Thus, to make the solution more manageable, we omit equations for the proportional changes in quantities $\hat{K}_{X}, \hat{K}_{Y}, \hat{L}_{X}, \hat{L}_{Y}, \hat{X}$, and $\hat{Y}$. We keep the proportional change in pollution, $\hat{Z}$, since that result is of interest as well, though it is a quantity and not a price.

\section{Results and Interpretations}

As just mentioned, we solve for effects of an increase in the pollution tax rate, $\tau_{Z}$, where $\hat{\tau}_{X}=\hat{\tau}_{Y}=\hat{\tau}_{K}=\hat{\tau}_{L}=0 .{ }^{9}$ As shown in the Appendix, the general solutions are: ${ }^{10}$

$$
\begin{gathered}
\hat{p}_{Y}=\frac{\left(\theta_{Y L} \theta_{X K}-\theta_{Y K} \theta_{X L}\right) \theta_{Y Z}}{D}\left[A\left(e_{Z Z}-e_{K Z}\right)-B\left(e_{Z Z}-e_{L Z}\right)+\left(\gamma_{K}-\gamma_{L}\right) \sigma_{u}\right] \hat{\tau}_{Z}+\theta_{Y Z} \hat{\tau}_{Z} \\
\hat{w}=\frac{\theta_{X K} \theta_{Y Z}}{D}\left[A\left(e_{Z Z}-e_{K Z}\right)-B\left(e_{Z Z}-e_{L Z}\right)+\left(\gamma_{K}-\gamma_{L}\right) \sigma_{u}\right] \hat{\tau}_{Z} \\
\hat{r}=\frac{\theta_{X L} \theta_{Y Z}}{D}\left[A\left(e_{K Z}-e_{Z Z}\right)-B\left(e_{L Z}-e_{Z Z}\right)-\left(\gamma_{K}-\gamma_{L}\right) \sigma_{u}\right] \hat{\tau}_{Z}
\end{gathered}
$$

\footnotetext{
${ }^{7}$ This formulation does not preclude household disutility from pollution. Rather, the utility function is assumed to be separable in pollution (or environmental quality). See Carbone and Smith (2004) for an analysis of the impact of non-separability of air quality and leisure in utility.

${ }^{8}$ Harberger (1962) chose $w$ as numeraire and interpreted the expression for $d r$ as the change in the return to capital relative to labor. In this model, we provide expressions for both $\hat{w}$ and $\hat{r}$. These results can be compared to those of Harberger by considering the value of $\hat{r}-\hat{w}$.

${ }^{9}$ All of the results have the same magnitude and opposite sign if the pollution tax is reduced. The other taxes do not change, but they are still in the model since firms and consumers in the initial equilibrium are responding to net-of-tax prices. If the levels of those tax rates appear in the solution for a price change, it means that the effect of $\tau_{\mathrm{Z}}$ on that price depends on the level of existing tax rates. The model here could be solved in a way that allows these other taxes to change. Thus it could be used with a revenue-neutrality constraint, so that an increase in the pollution tax is offset by a decrease in some other tax.

${ }^{10}$ If solely in terms of exogenous parameters, the expression for $\hat{Z}$ would be long. The three preceding equations can be substituted into the fourth to get that closed-form solution, as done in special cases below.
} 


$$
\begin{aligned}
\hat{Z}= & -\frac{1}{C}\left[\theta_{Y K}\left(\beta_{K}\left(e_{K K}-e_{Z K}\right)+\beta_{L}\left(e_{L K}-e_{Z K}\right)+\sigma_{u}\right) \hat{r}\right. \\
& +\theta_{Y L}\left(\beta_{K}\left(e_{K L}-e_{Z L}\right)+\beta_{L}\left(e_{L L}-e_{Z L}\right)+\sigma_{u}\right) \hat{w} \\
& \left.+\theta_{Y Z}\left(\beta_{K}\left(e_{K Z}-e_{Z Z}\right)+\beta_{L}\left(e_{L Z}-e_{Z Z}\right)+\sigma_{u}\right) \hat{\tau}_{Z}\right]
\end{aligned}
$$

where $\gamma_{K} \equiv \frac{\lambda_{K Y}}{\lambda_{K X}}=\frac{K_{Y}}{K_{X}}$ and $\gamma_{L} \equiv \frac{\lambda_{L Y}}{\lambda_{L X}}=\frac{L_{Y}}{L_{X}}$. Also, for convenience, this solution combines notation into definitions where $\beta_{K} \equiv \theta_{X K} \gamma_{K}+\theta_{Y K}, \beta_{L} \equiv \theta_{X L} \gamma_{L}+\theta_{Y L}, \quad A \equiv$ $\gamma_{L} \beta_{K}+\gamma_{K}\left(\beta_{L}+\theta_{Y Z}\right), \quad B \equiv \gamma_{K} \beta_{L}+\gamma_{L}\left(\beta_{K}+\theta_{Y Z}\right)$, and $C \equiv \beta_{K}+\beta_{L}+\theta_{Y Z}$. It is readily apparent that $A>0, \quad B>0$, and $C>0$. The denominator is $D \equiv C \sigma_{X}+A\left[\theta_{X K} \theta_{Y L}\left(e_{K L}-e_{L Z}\right)\right.$ $\left.\theta_{X L} \theta_{Y K}\left(e_{K K^{-}} e_{K Z}\right)\right]-B\left[\theta_{X K} \theta_{Y L}\left(e_{L L}-e_{L Z}\right)-\theta_{X L} \theta_{Y K}\left(e_{K L}-e_{K Z}\right)\right]-\left(\gamma_{K}-\gamma_{L}\right) \sigma_{u}\left(\theta_{X K} \theta_{Y L}-\theta_{X L} \theta_{Y K}\right)$.

While the interpretation of this general solution is limited by its complexity, some basic effects can be identified. For example, the last term in equation (11b) or (11c) is the "output effect" of Mieszkowski (1967): a tax on emissions is a tax only in the dirty sector and therefore reduces output (in a way that depends on consumer demand via $\sigma_{u}$ ). Less output means less demand for all inputs, but particularly the input used intensively in that sector. The term $\left(\gamma_{K}-\gamma_{L}\right)$ is positive when the dirty sector is capital-intensive. Then, assuming $D>0$, the output effect places relatively more burden on capital. Whether this intuitive results holds depends on the sign of the denominator $D$, however, and this complicated expression cannot be signed in this general solution.

Furthermore, the first two terms in equation (11b) or (11c) represent "substitution effects". As pollution become more costly, the dirty sector seeks to adjust its demand for all three inputs. How it does so is determined by the Allen elastiticies of substitution, which figure prominently in those first two terms. The constants $A$ and $B$ also come into play, weighing the impact of the elasticities on the incidence results. These constants can be signed, but their magnitudes are complicated functions of the factor share parameters, making an interpretation difficult from these general solutions alone.

Thus, while several effects are at work, their combination and interactions are quite difficult to analyze in these equations. We therefore isolate each effect by assuming away the other effects in a series of special cases. Although $A>0, B>0$, and $C>0$, the denominator $D$ cannot be signed, and so nothing definitive can be said yet about the effect of the pollution tax on the output price (11a), factor prices $(11 \mathrm{~b}, \mathrm{c})$, or even on the amount of pollution (11d). In fact, an increase in the pollution tax might increase pollution. ${ }^{11}$ Thus the following special cases are also useful to seek definitive results.

Before proceeding, consider implications for who bears the burden of this tax. On the sources side, the interpretation of $\hat{w}=\hat{r}=0$ is not that factors bear no burden, but

\footnotetext{
${ }^{11}$ DeMooij and Bovenberg (1998) obtain the same perverse result. In our model, it is possible with certain extreme parameter values. For an example that satisfies all of the restrictions from Allen (1938), suppose $\lambda_{K X}=0.2, \lambda_{L X}=0.1, \theta_{X K}=0.9, \theta_{Y K}=0.72, \theta_{Y Z}=0.1, e_{K L}=2, e_{K Z}=-1, e_{L Z}=5, e_{Z Z}=-1.8$, and $\sigma_{u}=$ $\sigma_{X}=1$. Capital and pollution are complements, while labor and pollution are strong substitutes. The increase in $p_{Z}$ has a "direct effect" that reduces pollution (since $e_{Z Z}=-1.8$ ) but a larger indirect effect that raises pollution. The $10 \%$ higher $p_{Z}$ decreases demand for capital $\left(e_{K Z}=-1\right)$ and decreases its return $(\hat{r}=$ -.0025). This reduction in $r$ serves to increase demand for labor $\left(e_{K L}=2\right)$. This labor is hard to get from the other sector $X$, which is capital-intensive and small, so $w$ rises steeply $(\hat{w}=.0223)$. This big increase in $w$ has a big positive effect on emissions $\left(e_{Z L}=5\right)$. The net result is $0.197 \%$ more emissions.
} 
that their burdens are in proportion to their shares of national income (both $w$ and $r$ fall in real terms when $p_{X}$ is numeraire and $p_{Y}$ rises). Thus, any $\hat{w}>0$ just means that labor's burden is less than its share of income. For labor to gain, the wage must rise by more than the overall price index $p \equiv \varphi p_{X}+(1-\varphi) p_{Y}$, where $\varphi$ is the share of total expenditure on $X$. If $\hat{w}=\hat{p}$, then labor bears no burden, and all of the burden must be on capital. And this discussion presumes that both factors spend similarly on the two goods; on the uses side, if $p_{Y}$ rises, the pollution tax places more burden on anybody who spends more than the average fraction of their income on the polluting good.

\section{Case 1: Equal Factor Intensities}

First, consider the case where both industries have the same factor intensities, that is, both are equally capital (and labor) intensive. This amounts to setting $\gamma_{L}$ and $\gamma_{K}$ equal to each other. Let their common value be $\gamma$, and note that this condition implies that $L_{Y} / L_{X}=K_{Y} / K_{X}$. In this case, the solution to the system of equations is:

$$
\begin{gathered}
\hat{p}_{Y}=\theta_{Y Z} \hat{\tau}_{Z} \\
\hat{w}=\frac{-\theta_{X K} \theta_{Y Z} \gamma\left(e_{K Z}-e_{L Z}\right)}{D_{1}} \hat{\tau}_{Z} \\
\hat{r}=\frac{\theta_{X L} \theta_{Y Z} \gamma\left(e_{K Z}-e_{L Z}\right)}{D_{1}} \hat{\tau}_{Z} \\
\hat{Z}=\frac{-\sigma_{u} \theta_{Y Z}-\theta_{Y Z}\left(\beta_{K}\left(e_{K Z}-e_{Z Z}\right)+\beta_{L}\left(e_{L Z}-e_{Z Z}\right)\right)}{\gamma+1} \hat{\tau}_{Z} \\
-\frac{\left[\theta_{X L} \theta_{Y K}\left(\beta_{K}\left(e_{K Z}-e_{K K}\right)+\beta_{L}\left(e_{K Z}-e_{K L}\right)+\beta_{K}\left(e_{K L}-e_{L Z}\right)+\beta_{L}\left(e_{L L}-e_{L Z}\right)\right)\right] \gamma \theta_{Y Z}\left(e_{L Z}-e_{K Z}\right)}{D_{1}(\gamma+1)} \hat{\tau}_{Z}
\end{gathered}
$$

where $D_{1} \equiv \sigma_{X}-\theta_{X L} \theta_{Y K} \gamma\left(e_{K K}-e_{K L}\right)-\theta_{X K} \theta_{Y L} \gamma\left(e_{L L}-e_{K L}\right)$.

One of the most striking observations from this solution is how the general expression for $\hat{p}_{Y}$ in (11a) reduces to such a simple expression in (12a). In this special case, then, we can provide a definite sign:

Proposition 1A: In Case 1, $\hat{p}_{Y}>0$. Proof: Since $\hat{\tau}_{Z}>0$, Equation (12a) implies $\hat{p}_{Y}>0$.

Furthermore, the increase in the pollution tax affects this relative price only through the share that pollution constitutes of output, $\theta_{Y Z}$. The fact that equation (11a) of the general solution is more complicated implies that the capital and labor intensities of production also effect $p_{Y}$ in the general case. Here, those effects have been assumed away, and the uses side of the incidence of an environmental tax is clear: consumers of the dirty good bear a cost of the tax increase.

To interpret the incidence on the sources side, or the effect of a change in the pollution tax on returns to inputs, we must know something about the sign of the denominator $D_{l}$. Note that it can be written as:

$$
D_{1}=\left(\sigma_{X}-\theta_{X L} \theta_{Y K} \gamma e_{K K}-\theta_{X K} \theta_{Y L} \gamma e_{L L}\right)+\gamma\left(\theta_{X L} \theta_{Y K}+\theta_{X K} \theta_{Y L}\right) e_{K L} .
$$


Therefore, $D_{1}>0$ if and only if $e_{K L}>\frac{-\sigma_{X}+\theta_{X L} \theta_{Y K} \gamma e_{K K}+\theta_{X K} \theta_{Y L} \gamma e_{L L}}{\gamma\left(\theta_{X L} \theta_{Y K}+\theta_{X K} \theta_{Y L}\right)}$. Call this last inequality "Condition 1". The expression to the right of the inequality sign is strictly negative, so $e_{K L}>0$ is sufficient but not necessary for Condition 1 . Remember that $e_{i j}$ is positive whenever inputs $i$ and $j$ are substitutes, and negative for complements. To make the denominator $D_{1}>0$, it is not necessary that capital and labor are substitutes in production of $Y\left(e_{K L}>0\right)$, but only that they are not too complementary (Condition 1).

With that condition, we can interpret the effect of a change in the pollution tax rate on the returns to factors of production.

Proposition 1B: In Case 1, under Condition 1, $\hat{w}>0$ and $\hat{r}<0$ if and only if $e_{L Z}>e_{K Z}$. Proof: Since $D_{1}>0$ under Condition 1, Equations (12b) and (12c) imply this result.

A special case of $1 \mathrm{~B}$ is where labor and pollution are substitutes in sector $Y$, while capital and pollution are complements (that is, $e_{L Z}>0$ and $e_{K Z}<0$ ). In this case, the condition $e_{L Z}>e_{K Z}$ of Proposition $1 \mathrm{~B}$ holds, and $\tau_{Z}$ raises the wage. ${ }^{12}$ It is not necessary, however, for these terms to have opposite signs. Even if both capital and labor are substitutes for pollution, the relative price of labor still rises from an increase in the pollution tax as long as labor is a better substitute for pollution than is capital.

It is also of interest and quite counterintuitive to note when the above proposition does not hold. If the value of $D_{l}$ is negative, then the results are exactly the opposite.

Proposition 1C: In Case 1, but where Condition 1 does not hold, $\hat{w}>0$ and $\hat{r}<0$ if and only if $e_{L Z}<e_{K Z}$. Proof: $D_{1}<0$, and Equations (12b) and (12c).

Normally with $e_{L Z}<e_{K Z}$, we would say that capital is a better substitute for pollution, so the pollution tax would tend to increase demand for capital and hence to increase $r$. This effect is more than offset, however, when $e_{L K}$ is sufficiently negative (Condition 1 does not hold). Capital and labor are complementary inputs, and the increased demand for capital also leads to an increased demand for labor. With a sufficiently high degree of complementarity, this effect dominates, and $w$ increases relative to $r$. While we would not necessarily expect this case to be common, it demonstrates a perverse possibility: even when both sectors have equal factor intensities, the better substitute for pollution can bear more of the burden of a tax on pollution.

\section{Case 2: Equal Factor Intensities and $e_{K Z}=e_{L Z}$}

On the border between those two propositions, when capital and labor are equally good substitutes for pollution, then neither bears a disproportionate burden of the tax. In addition to $\gamma_{K}=\gamma_{L}=\gamma$, suppose that $e_{L Z}=e_{K Z}$, and call this Case 2. ${ }^{13}$

\footnotetext{
${ }^{12}$ Note that the change in the wage rate always has the opposite sign as the change in the rental rate. This follows directly from the choice of $X$ as numeraire and the zero-profit equation (6). This relationship need not hold for other choices of numeraire. Only the relative change in the returns to capital and labor is of interest here, and this value is independent of the choice of numeraire.

${ }^{13}$ For an even simpler model, one could also assume $e_{K L}=\sigma_{X}=0$. These additional conditions are sufficient to think of the clean inputs $L$ and $K$ in fixed proportions and therefore as a single composite input. Sector $X$ uses only this input with no ability to substitute. Sector $Y$ has effectively only two inputs between which it can substitute: one is pollution and the other is this clean input. The results with these assumptions are identical to the results in Case 2, however, so we do not need these additional assumptions.
} 
Proposition 2A: In Case 2, $\hat{w}=0, \hat{r}=0, \hat{p}_{Y}=\theta_{Y Z} \hat{\tau}_{Z}$, and

$$
\hat{Z}=\frac{-\sigma_{u}-\left(\beta_{K}+\beta_{L}\right)\left(e_{L Z}-e_{Z Z}\right)}{\gamma+1} \theta_{Y Z} \hat{\tau}_{Z} .
$$

Proof: Equations (12a-d), substituting in $e_{K Z}=e_{L Z}$.

For factor prices, as in Case 1, equal factor intensities eliminates the output effect of Mieszkowski (1967). The additional assumption of equal substitution elasticities in Case 2 eliminates his substitution effect. Without either of these effects, the change in the pollution tax has no effect on the relative prices of capital and labor. Then the effect on the price of the dirty good is the same as in Case 1. More interesting in this case is that we can finally sign the effect of a change in the pollution tax on pollution.

Proposition 2B: In Case 2, $\hat{Z}<0$. Proof: In equation (13), note that $e_{\mathrm{ZZ}}$ is negative, but that all of the other parameters are positive. ${ }^{14}$

The purpose of this example is to reduce the general model to the simple case where the tax on pollution is said to have two effects that both reduce pollution. The "substitution effect" is the second term in the numerator of (13), where $\tau_{Z}$ increases the relative price of pollution, which reduces pollution per unit output. The "output effect" is the first term in (13), where $\tau_{Z}$ increases the price of output, which reduces total demand. ${ }^{15}$ Thus, pollution is definitely reduced by the imposition of the tax on pollution. Somewhat surprisingly, this intuitive result cannot be proven in the more general case.

\section{Case 3: Fixed Input Proportions $\left(e_{i j}=0\right)$}

By eliminating factor intensity differences, the special cases above concentrate on the signs of input demand elasticities. Now we eliminate the differential effects of input demand elasticities in order to concentrate on relative factor intensities, $\left(\gamma_{K}-\gamma_{L}\right)$. If this value is positive, then industry $Y$ is capital-intensive.

In this narrow special case, the production of $Y$ requires inputs in fixed proportions. We then expect no substitution effect, but only the output effect arising from the implicit tax on $Y$ associated with an increase in the tax on pollution. This absence of a substitution effect is precisely what materializes in the solution: ${ }^{16}$

$$
\begin{gathered}
\hat{p}_{Y}=\frac{C \sigma_{X} \theta_{Y Z}}{D_{3}} \hat{\tau}_{Z} \\
\hat{w}=\frac{\left(\gamma_{K}-\gamma_{L}\right) \theta_{X K} \theta_{Y Z} \sigma_{u}}{D_{3}} \hat{\tau}_{Z} \\
\hat{r}=\frac{-\left(\gamma_{K}-\gamma_{L}\right) \theta_{X L} \theta_{Y Z} \sigma_{u}}{D_{3}} \hat{\tau}_{Z}
\end{gathered}
$$

\footnotetext{
${ }^{14}$ In the more general case, $e_{L Z}$ could be positive or negative, but here where $e_{L Z}=e_{K Z}$, the fact that $e_{Z Z}$ must be negative implies that $e_{L Z}=e_{K Z}$ must be positive.

${ }^{15}$ This terminology appears in pollution models. Everywhere else in this paper, we use Mieskowski's (1967) terminology where output and substitution effects refer to effects on factor prices.

${ }^{16}$ The expression for $\hat{Z}$ can be evaluated using the other three expressions, but it is not included here because it does not prove illuminating.
} 
where $D_{3}=C \sigma_{X}-\left(\gamma_{K}-\gamma_{L}\right) \sigma_{u}\left(\theta_{X K} \theta_{Y L}-\theta_{X L} \theta_{Y K}\right)$. It can be shown that $\left(\gamma_{K}-\gamma_{L}\right)$ and $\left(\theta_{X K} \theta_{Y L}-\theta_{X L} \theta_{Y K}\right)$ always have opposite sign, so $D_{3}>0$. Just as in cases above, the price of the dirty good relative to the clean good increases unambiguously in response to an increase in the tax on pollution $\left(\hat{p}_{Y}>0\right)$.

More interesting is the effect on the relative return to labor and capital. The sign of each of those two changes is based only on the relative factor intensities of the two industries, $\gamma_{K}-\gamma_{L}$. We can write this conclusion as the following:

Proposition 3: In Case 3, if $Y$ is capital-intensive, then $\hat{w}>0$ and $\hat{r}<0$. Proof: Equations $(14 \mathrm{~b}, \mathrm{c})$, since $D_{3}>0$, and $Y$ being capital-intensive means $\gamma_{K}-\gamma_{L}>0$.

The interpretation is solely in terms of the output effect for sector $Y$. Because of fixed input proportions $\left(e_{i j}=0\right)$, a pollution tax increase is equivalent to a tax on output $Y$ and leads to decreased output of that good. Therefore, sector $Y$ demands less labor and less capital. If $Y$ is capital-intensive, then the fall in demand for capital exceeds the fall in demand for labor, and hence $r$ falls relative to $w$. This simple case helps establish the presumption for the more surprising result of the next section.

\section{Case 4: Equal Elasticities of Factor Demand}

To abstract from differential input demand elasticities, it is not necessary to suppose that all are zero. A less restrictive way to do this is to suppose that all of the own-price Allen elasticities $e_{i i}$ are equal to a negative constant $a_{1}$, and that all of the cross-price elasticities, $e_{i j}$ for $i \neq j$, are equal to a positive constant $a_{2}{ }^{17}$ Furthermore, define $\alpha \equiv\left(a_{2}-a_{1}\right)>0$. The solution to the system then is:

$$
\begin{gathered}
\hat{p}_{Y}=\frac{\theta_{Y Z}}{D_{4}}\left\{\theta_{Y Z} \alpha\left(\theta_{Y K} \theta_{X L}-\theta_{Y L} \theta_{X K}\right)\left(\gamma_{K}-\gamma_{L}\right)+C \sigma_{X}+\alpha\left(A \theta_{X L} \theta_{Y K}+B \theta_{Y L} \theta_{X K}\right)\right\} \hat{\tau}_{Z} \\
\hat{w}=\frac{\left(\gamma_{K}-\gamma_{L}\right) \theta_{X K} \theta_{Y Z}\left(\sigma_{u}-\theta_{Y Z} \alpha\right)}{D_{4}} \hat{\tau}_{Z} \\
\hat{r}=\frac{-\left(\gamma_{K}-\gamma_{L}\right) \theta_{X L} \theta_{Y Z}\left(\sigma_{u}-\theta_{Y Z} \alpha\right)}{D_{4}} \hat{\tau}_{Z}
\end{gathered}
$$

where $D_{4}=C \sigma_{X}+\alpha\left(A \theta_{X L} \theta_{Y K}+B \theta_{Y L} \theta_{X K}\right)-\left(\gamma_{K}-\gamma_{L}\right) \sigma_{u}\left(\theta_{X K} \theta_{Y L}-\theta_{X L} \theta_{Y K}\right)$. In this case, the denominator $D_{4}$ is definitely positive. The second term is positive, since $\alpha>0, A>0$, and $B>0$. And the remaining terms are the same as in $D_{3}>0$. Thus $D_{4}>0$.

As in the other special cases, the sign of the change in the price of the dirty good relative to the price of the clean good is unambiguous.

Proposition 4A: In Case 4, $\hat{p}_{Y}>0$. Proof: since $\left(\theta_{Y K} \theta_{X L}-\theta_{Y L} \theta_{X K}\right)$ has the same sign as $\left(\gamma_{K}-\gamma_{L}\right)$, and $D_{4}>0$, the coefficient in equation (15a) is positive.

We can now interpret the changes in factor prices in terms of an output effect and substitution effect in the polluting industry. The sign of the change in factor prices in $(15 \mathrm{~b}, \mathrm{c})$ is dependent on the signs of $\left(\gamma_{K}-\gamma_{L}\right)$ and $\left(\sigma_{u}-\theta_{Y Z} \alpha\right)$. The former is positive

\footnotetext{
${ }^{17}$ Our Appendix discusses restrictions demonstrated by Allen (1938). Since $e_{i i}$ must be negative, Case 4 assumes that the matrix of $e_{i j}$ has $a_{1}<0$ down the diagonal and $a_{2}>0$ everywhere else.
} 
when $Y$ is capital-intensive. In the latter, $\alpha$ is a measure of the overall ability of firms in sector $Y$ to substitute among inputs. It is equal to $e_{i j}-e_{i i}$, so a larger $\alpha$ means easier substitution away from the more costly input $\left(e_{i i}<0\right)$ and into the other inputs $\left(e_{i j}>0\right)$. Also, $\sigma_{u}$ represents the ability of consumers to substitute between $X$ and $Y$. Thus, in combination, the expression $\left(\sigma_{u}-\theta_{Y Z} \alpha\right)$ represents whether it is relatively easier for consumers to substitute between goods $X$ and $Y$ than for producers of $Y$ to substitute among their three inputs $K, L$, and $Z$. This interpretation leads to the following proposition about an increase in the pollution tax $\tau_{Z}$ :

Proposition 4B: In Case 4, when sector $Y$ is capital intensive, then $\hat{w}>0$ and $\hat{r}<0$ whenever $\sigma_{u}>\theta_{Y Z} \alpha$. When sector $Y$ is labor intensive, then $\hat{w}<0$ and $\hat{r}>0$ whenever $\sigma_{u}>\theta_{Y Z} \alpha$. Proof: equations (15b) and (15c), since $D_{4}>0$.

To explain, $\hat{\tau}_{Z}>0$ induces a substitution effect for producers of $Y$ that increases demand for $K$ and could be expected to increase $r$. In addition, however, the output effect raises the price of $Y$ and reduces production. When $Y$ is capital intensive, this output effect reduces overall demand for capital and would tend to decrease $r$. These two effects work in opposite directions. If $\sigma_{u}>\theta_{Y Z} \alpha$, then the output effect dominates the substitution effect and less capital is demanded by sector $Y$. When sector $Y$ is capital-intensive, its reduced demand for capital outweighs sector $X$ 's increased use, and the economy-wide $r / w$ falls. Hence the result in Proposition 4B.

This proposition includes both the intuitive result above and the reverse counterintuitive result: abstracting from different cross-price elasticities, capital intensity in the dirty industry can lead to a disproportionately high burden of the pollution tax on labor rather than on capital. Again, capital intensity of $Y$ has two opposite effects. On the one hand, it reduces $r$ through the output effect, since consumers demand less of the capital-intensive good. However, $\sigma_{u}<\theta_{Y Z} \alpha$ means that effect is relatively small. The larger substitution effect means that firms are trying to substitute out of $Z$ and into both $K$ and $L$. The firms in $Y$ want to increase both factors in proportion to their own use, which is capital-intensive, but they must get that capital from $X$, which is labor intensive. They can only get that extra capital by bidding up its price.

\section{Case 5: All Equal Cross-Price Substitution Elasticities}

A final special case can help with intuition and relate our model to other models in the literature. Here, we impose no constraints on factor intensities but suppose that all cross-price substitution elasticities have the same value $\left(\sigma_{u}=e_{K L}=e_{K Z}=e_{L Z}=c\right.$, some constant). We then have the following proposition:

Proposition 5A: In Case 5, regardless of factor intensities, then $\hat{w}=0, \hat{r}=0$, $\hat{p}_{Y}=\theta_{Y Z} \hat{\tau}_{Z}$, and $\hat{Z}=-c \hat{\tau}_{Z}$. Proof: Substitute $c$ into all of equations (11).

It is interesting that these results are similar to those of case 2 even though case 2 employs different assumptions (equal factor intensities and $e_{K Z}=e_{L Z}$ ). Instead, this case with equal substitution elastiticies is almost Cobb-Douglas, but a smaller elasticity $c<1$ implies that the tax $\tau_{Z}$ has less effect on pollution. It can be shown that Cobb-Douglas production in the $Y$ sector means, $e_{K L}=e_{K Z}=e_{L Z}=1$ and $e_{i i}=\left(\theta_{Y i}-1\right) / \theta_{Y i}$ for each input $i$. Cobb-Douglas utility means $\sigma_{u}=1$. Then, with these assumptions, we have:

Proposition 5B: If utility and production of $Y$ are Cobb-Douglas, then $\hat{w}=0, \hat{r}=0$, $\hat{p}_{Y}=\theta_{Y Z} \hat{\tau}_{Z}$, and $\hat{Z}=-\hat{\tau}_{Z}$. Proof: Substitute the elasticity values into all equations (11). 
This Cobb-Douglas case is worth stating explicitly because of its clear intuition. Consumers spend a constant fraction of income on $Y$, and the firms in $Y$ spend a constant fraction of sales revenue to pay for pollution. Thus, total spending $\tau_{Z} Z$ is constant. Then any increase in the pollution tax implies the same percent fall in pollution and no effect on any other factor of production. In fact, the price $p_{Y}$ rises by the same percentage that the quantity $Y$ falls.

\section{Numerical Analysis}

To explore the likely size of these effects, we now assign plausible values to parameters. The goal here is not to calculate a point estimate for effects of a pollution tax on pollution and factor prices, as this model is too simple for that purpose. Rather, the goal is to put numerical magnitudes on the theoretical effects derived above, to see how much these outcomes might be affected by changes in key parameters. We therefore vary the factor intensities and substitution elasticities. Other parameters are chosen to approximate the current U.S. economy or to match estimates in the available literature. Though many of these parameters have not been estimated in the form required here, other structural models may be similar enough to use their parameter values in our model.

For a definition of the "dirty" sector, we use the top thirteen polluting industries from the EPA's Toxic Release Inventory for 2002. ${ }^{18}$ All other industries are deemed "clean" for present purposes. We then use industry-level data on labor and capital employed in the U.S., from Jorgenson and Stiroh (2000). ${ }^{19}$ When we add labor and capital across industries within each sector, we find that the 13 most polluting industries represent about $20 \%$ of factor income. Therefore, our first "stylized fact" is that the clean sector is $80 \%$ of income. Using the same data, we find that the capital share of factor income is .3985 in the clean sector and .4105 in the dirty sector. ${ }^{20}$ Thus the dirty sector is slightly capital-intensive, as consistent with prior findings (e.g. Antweiler et al, 2001, p. 879). The difference is quite small, however, and we wish to avoid the perception that we are trying to calculate incidence with such precision. Appropriate rounding suggests that the capital share in both sectors is about $40 \%$, and so that is the second stylized fact used here (as a starting point, before sensitivity analysis). ${ }^{21}$

In the clean sector, the implication is that $\theta_{X K}$ is 0.40 , and $\theta_{X L}$ is 0.60 (so $K / L$ is $2 / 3$ ). In the dirty sector, however, these data on labor and capital do not help determine the fraction of output attributed to the value of pollution $\left(\theta_{Y Z}\right)$. This parameter is not in available data, since most industries do not pay an explicit price for pollution. For most

\footnotetext{
${ }^{18}$ The top 13 polluters are those with at least 120,000,000 pounds of on- and off-site reported releases of all chemicals monitored by the TRI (nearly 650 listed at http://www.epa.gov/tri/chemical/index.htm). These industries are metal mining, electric utilities, chemicals, primary metals, food, paper, plastics, transportation equipment, petroleum, fabricated metals, stone/clay/glass, lumber, and electrical equipment. These data are publicly available at http://www.epa.gov/triexplorer/industry.htm.

${ }^{19}$ Available online at http://post.economics.harvard.edu/faculty/jorgenson/data/35klem.html.

${ }^{20}$ These values are also consistent with other literature. The capital share is similar across studies, though again no study considers clean industries only. Griliches and Mairesse (1998) conclude that the capital share is approximately 0.4, and Blundell and Bond (1998) use GMM to yield an estimate of approximately 0.3 , which rises to 0.45 when constant returns to scale is imposed.

${ }^{21}$ Other definitions of the dirty sector might yield more divergent factor intensities. If it includes only utilities and chemicals, for example, then capital is $55 \%$ of factor income. Also, however, that dirty sector is only $8 \%$ of the economy. In that case we found very small changes in $w$ and $r$, and so those results are not so interesting. A general equilibrium model is not necessary when the taxed sector is small.
} 
pollutants in most industries, this value is implicit - a shadow value, or scarcity rent. Therefore, somewhat arbitrarily, we set $\theta_{Y Z}$ to 0.25 , and so our third stylized fact is that the dirty industry spends $25 \%$ of its sales revenue on the pollution input. ${ }^{22}$ For the remaining $75 \%$ to have the same $K / L$ ratio as the clean sector, $\theta_{Y K}$ must be 0.30 , and $\theta_{Y L}$ must be 0.45 . In fact, given various equations of the model, the three stylized facts are enough to determine all of the remaining parameters shown in Table $1 .^{23}$

\begin{tabular}{|cc|}
\hline $\begin{array}{c}\text { Table 1: Data and parameters for the case with } \\
\text { equal factor intensities (where } \theta_{Y Z}=.25 \text { ) }\end{array}$ \\
\hline$K_{Y}=0.0800$ & $L_{Y}=0.1200$ \\
$K_{X}=0.3200$ & $L_{X}=0.4800$ \\
$\lambda_{K Y}=0.2000$ & $\lambda_{L Y}=0.2000$ \\
$\lambda_{K X}=0.8000$ & $\lambda_{L X}=0.8000$ \\
$\theta_{Y K}=0.3000$ & $\theta_{Y L}=0.4500$ \\
$\theta_{X K}=0.4000$ & $\theta_{X L}=0.6000$ \\
\hline
\end{tabular}

No empirical estimates of substitution parameters are available specifically for our definition of the dirty sector. The clean sector is $80 \%$ of factor income, however, so an economy-wide estimate represents a decent approximation of $\sigma_{X}$ for the clean sector. Lovell (1973) and Corbo and Meller (1982) estimate the elasticity of substitution between capital and labor for all manufacturing industries. They find an elasticity of unity, which we employ for $\sigma_{X} \cdot{ }^{24}$ We also use unity for the elasticity of substitution in consumption between the clean and dirty goods, $\sigma_{u}{ }^{25}$

The only further parameters needed are the $e_{i j}$ input demand elasticities in the dirty sector. The model includes six of these parameters, but only three can be set independently. ${ }^{26}$ Therefore, we vary only the three cross-price elasticities, which effectively sets the other parameters. To the best of our knowledge, these cross-price elasticities have never been estimated with inputs defined as labor, capital, and pollution. ${ }^{27}$ We therefore allow them to take alternative values of $-1,-1 / 2,0,1 / 2$, and 1 . As these parameters vary, we consider the implications for the results $\left(\hat{p}_{Y}, \hat{w}, \hat{r}, \hat{Z}\right)$.

\footnotetext{
${ }^{22}$ This parameter would be under-estimated using data from an emissions permit market such as the one in place for sulfur dioxide of electric utilities, since most pollutants are restricted by mandates rather than permits or taxes. If shareholders own the right to emit a restricted amount of any pollutant, then they earn a scarcity rent that we would characterize as the return $p_{Z} Z$. In available data, this return might appear as part of the normal return to capital of the shareholders. In effect, then, we suppose that existing pollution restrictions and shadow prices are first converted to their equivalent explicit tax rates $\tau_{Z}$. We then evaluate marginal effects of environmental policy by calculating the effects of a small increase in that pollution tax.

${ }^{23} \mathrm{We}$ define a unit of any input or output such that all initial prices are one $\left(p_{X}=p_{Y}=p_{K}=p_{L}=p_{Z}=1\right)$. Then zero profit conditions imply $X=K_{X}+L_{X}$ and $Y=K_{Y}+L_{Y}+Z$. We consider an economy with total factor income equal to one (which could be in billions or trillions). Then $K_{X}+K_{Y}+L_{X}+L_{Y}=1$, and factor shares in each industry are enough to determine all $\lambda$ 's and $\theta$ 's.

${ }^{24}$ In a more recent paper estimating this parameter, Claro (2003) finds elasticities of approximately 0.8 , which is close to one. Babiker et al (2003) also use $\sigma_{X}=1$ in their computational model.

${ }^{25}$ This is the same initial value used by Fullerton and Metcalf (2001). Little evidence exists on the substitution in utility between goods produced using pollution and those produced otherwise.

${ }^{26}$ The Appendix defines $a_{i j}=\theta_{Y j} e_{i j}$, where the parameters must satisfy $a_{i L}+a_{i K}+a_{i Z}=0$ for all $i$. These restrictions together effectively determine all six Allen elasticities from only three.

${ }^{27}$ Humphrey and Moroney (1975) estimate Allen elasticities using capital, labor, and natural resource products. Bovenberg and Goulder (1997) use estimates of elasticities between labor, capital, energy, and
} 
In performing these calculations, we always use a $10 \%$ increase in the pollution tax. Table 2 allows the Allen elasticities $e_{K Z}$ and $e_{L Z}$ to vary, holding constant the factor intensities. ${ }^{28}$ Notice first that the change in pollution in the last column is always negative, but the magnitude of the change varies drastically in a way that depends on the two varied parameters. The smallest change in pollution occurs when both of those parameters are zero $(\hat{Z}=-.0200$ in row 2$)$, but it is also small whenever the two are of opposite signs (e.g. row 1 or 5). The change in pollution is larger when both are positive, and it is largest in the Cobb-Douglas case where all three cross-price Allen elasticities are equal to one (row 12). As consistent with proposition $5 \mathrm{~B}$, this row shows $\hat{Z}=-\hat{\tau}_{Z}$.

\begin{tabular}{|c|c|c|c|c|c|c|}
\hline Row & $e_{K Z}$ & $e_{I Z}$ & $\hat{w}$ & $\hat{r}$ & ל, & $\hat{Z}$ \\
\hline 1 & 10 & -05 & -000335 & 005 & 02500 & 02559 \\
\hline 2 & 0.0 & 0.0 & 0.00000 & 0.00000 & 0.02500 & -0.02000 \\
\hline 3 & 0.5 & 0.0 & -0.00112 & 0.00169 & 0.02500 & -0.03573 \\
\hline 4 & 1.0 & 0.0 & -0.00221 & 0.00331 & 0.02500 & -0.05094 \\
\hline 5 & -0.5 & 0.5 & 0.00230 & -0.00345 & 0.02500 & -0.02690 \\
\hline 6 & 0.0 & 0.5 & 0.00113 & -0.00169 & 0.02500 & -0.04373 \\
\hline 7 & 0.5 & 0.5 & 0.00000 & 0.00000 & 0.02500 & -0.06000 \\
\hline 8 & 1.0 & 0.5 & -0.00109 & 0.00164 & 0.02500 & -0.07574 \\
\hline 9 & -0.5 & 1.0 & 0.00341 & -0.00511 & 0.02500 & -0.04955 \\
\hline 10 & 0.0 & 1.0 & 0.00223 & -0.00335 & 0.02500 & -0.06693 \\
\hline 11 & 0.5 & 1.0 & 0.00110 & -0.00165 & 0.02500 & -0.08374 \\
\hline 12 & 1.0 & 1.0 & 0.00000 & 0.00000 & 0.02500 & -0.10000 \\
\hline
\end{tabular}

The changes in the wage rate and capital rental rate in Table 2 are always small, no more than about a half of a percent in either direction. The increase in output price is more substantial in Table 2, always $2.5 \%$. This result is no coincidence. With equal factor intensities, the simple result of Case 1 and equation (12a) is $\hat{p}_{Y}=\theta_{Y Z} \hat{\tau}_{Z}$. Thus, the $10 \%$ increase in $\tau_{Z}$ always raises the output price by $2.5 \%$.

The primary purpose of Table 2 is to illustrate the effects of different cross-price elasticities, as in Case 1 where both sectors have the same factor intensities. Indeed, since $e_{K L}=1$ satisfies Condition 1, the table reflects Proposition 1B where the pollution tax always imposes more burden on the relative complement to pollution, whether it be capital $\left(e_{K Z}<e_{L Z}\right)$ or labor $\left(e_{K Z}>e_{L Z}\right)$. When neither is a relative complement $\left(e_{K Z}=\right.$ $e_{L Z}$ ), both are burdened equally as in Proposition 2A (rows 2, 7, and 12).

materials. They interpret energy to be a proxy for pollution, strictly valid only if pollution is fixed per unit of energy. DeMooij and Bovenberg (1998) review such estimates and find that $e_{K L}=0.5, e_{K Z}=0.5$, and $e_{L Z}=0.3$ best summarize the existing literature. These figures suggest that capital might be a slightly better substitute for energy than is labor, but the difference is not precisely estimated. Their estimates are taken from data on Western European countries.

${ }^{28}$ The table does not contain every permutation of $e_{K Z}$ and $e_{L Z}$ between -1 and 1 , because not all permutations are possible. Both cannot be negative, since we know that at most one of the three cross-price elasticities is negative. Furthermore, we omit combinations that result in a positive value for any $e_{i i}$. Finally, Table 2 always uses $e_{K L}=1$. 
Since we know those directions from the theory, Table 2 only tells us about magnitudes. How much of the burden on the sources side is shifted from one factor to the other? For labor to bear no burden or to gain from raising this tax, the wage must rise by at least the overall price index $p \equiv \varphi p_{X}+(1-\varphi) p_{Y}$, where $\varphi=0.75$ is the share of expenditure on $X$. When $\hat{p}_{Y}=0.025$, the change in this price index is $\hat{p}=.00625$. Thus $\hat{w}=0.00625$ would mean that labor is held harmless, and capital bears the whole burden of the pollution tax. ${ }^{29}$ In Table 2, the largest $\hat{w}$ is 0.00341 (in row 9). In other words, labor can avoid "most" of the burden when the pollution tax induces the firm to use more labor $\left(e_{L Z}=1\right)$ and less capital $\left(e_{K Z}=-.5\right)$.

In the next table, we consider the impact of changes in factor intensities (with unchanging elasticities). We cannot just set the cross-price elasticities equal to each other, however, because then Proposition 5A says we get no effects on factor prices. Instead, all rows of Table 3 assume $e_{L Z}=1$ and $e_{K Z}=-.5$ (as in row 9 of Table 2, with the largest effects on factor prices). Then, with those elasticities fixed, we vary the factor intensities. The first column shows $\gamma_{K}-\gamma_{L}$, which is positive if the dirty sector is capital intensive. We vary this value from -0.25 to 0.25 , which effectively changes the "data" of the initial economy. We then calculate new parameters $\lambda$ and $\theta$ that are consistent with each other (and with a fixed overall size of each sector $X$ and $Y$ and fixed resource quantities $\bar{K}$ and $\bar{L}$ ). The second column shows corresponding increases in $\theta_{Y K}$ from 0.15 to 0.44 (and row 6 shows prior results with $\theta_{Y K}=0.30$ and $\theta_{X K}=0.40$ ).

\begin{tabular}{|cccccccc|}
\hline \multicolumn{8}{|c|}{ Table 3: Effects of a $10 \%$ increase in the pollution tax, varying factor } \\
intensity (with $e_{L Z}=1, e_{K Z}=-0.5, \theta_{Y Z}=.25$, and & \multicolumn{4}{c|}{$\left.\sigma_{X}=e_{K L}=\sigma_{u}=1\right)$} \\
\hline Row & $\gamma_{K}{ }^{-}{ }_{L}{ }^{\mathrm{a}}$ & $\theta_{Y K}$ & $\theta_{X K}$ & $\hat{w}$ & $\hat{r}$ & $\hat{p}_{Y}$ & $\hat{Z}$ \\
\hline 1 & -0.25 & 0.1515 & 0.4495 & 0.0018 & -0.0022 & 0.0258 & -0.0750 \\
2 & -0.20 & 0.1818 & 0.4394 & 0.0022 & -0.0028 & 0.0257 & -0.0699 \\
3 & -0.15 & 0.2118 & 0.4294 & 0.0025 & -0.0033 & 0.0256 & -0.0648 \\
4 & -0.10 & 0.2416 & 0.4195 & 0.0028 & -0.0039 & 0.0255 & -0.0597 \\
5 & -0.05 & 0.2710 & 0.4097 & 0.0031 & -0.0045 & 0.0253 & -0.0546 \\
$6^{\mathrm{b}}$ & 0.00 & 0.3000 & 0.4000 & 0.0034 & -0.0051 & 0.0250 & -0.0496 \\
7 & 0.05 & 0.3286 & 0.3905 & 0.0037 & -0.0057 & 0.0247 & -0.0445 \\
8 & 0.10 & 0.3566 & 0.3811 & 0.0039 & -0.0064 & 0.0243 & -0.0395 \\
9 & 0.15 & 0.3841 & 0.3720 & 0.0041 & -0.0070 & 0.0238 & -0.0346 \\
10 & 0.20 & 0.4110 & 0.3630 & 0.0044 & -0.0076 & 0.0233 & -0.0297 \\
11 & 0.25 & 0.4373 & 0.3542 & 0.0045 & -0.0083 & 0.0228 & -0.0248 \\
\hline
\end{tabular}

${ }^{a}$ Note that $\gamma_{K}-\gamma_{L}=K_{Y} / K_{X}-L_{Y} / L_{X}$.

${ }^{\mathrm{b}}$ Results in row 6 match those in Table 2, row 9.

The first five rows of Table 3 illustrate how labor can bear less than its share of the burden, even though the dirty sector is labor intensive, because labor is a better substitute for pollution. As the polluting sector is changed from labor intensive to capital intensive, the pollution tax burden is shown to shift even more onto capital. The fall in the rental rate enlarges from $0.22 \%$ to $0.83 \%$. The change in the wage is always positive,

\footnotetext{
${ }^{29}$ This threshold can be reached when the elasticities differ by greater amounts. Suppose $e_{K Z}=-1$ and $e_{L Z}$ $=3$, so that capital and pollution are complements, while labor and pollution are strong substitutes. Then $\hat{w}=.0082>.00625$, and labor gains.
} 
because labor is the better substitute for pollution, but $\hat{w}$ rises from 0.0018 to 0.0045 as the dirty sector becomes more capital-intensive. In this last row labor avoids "most" of the burden, relative to the threshold where $\hat{w}=0.00625$, but labor still cannot avoid all of the burden - even in this combination where labor is a better substitute for pollution and the dirty sector is very capital intensive.

In general, the factor intensities of the two industries are better estimated than are the Allen elasticities of substitution. In Table 3, the factor intensities are varied over a range that is much wider than the range of possible estimates, and still the proportional change in the wage rate varies by only 0.0027 (from 0.0018 to 0.0045 ). In contrast, Table 2 varies the cross-price Allen elasticities only from -0.5 to 1.0 , a range that is less wide than the range of possible estimates, and $\hat{w}$ varies by more than twice as much (by 0.0068 , from -0.0034 to +0.0034 ). Thus, for the incidence of the pollution tax, we conclude that the impact of factor intensities over the plausible range is less important than the impact of the elasticities of substitution between pollution and capital or labor.

\section{Conclusion}

Using a simple general equilibrium model of production with pollution, this paper has found the incidence of a pollution tax on the prices of outputs and on the returns to inputs. We present the system of equations that can be solved for the incidence of any tax on capital, labor, output, or pollution. A small increase in the pollution tax rate alters the return to labor relative to capital in a way that depends on the substitutability of labor for pollution, the substitutability of capital for pollution, and the relative factor intensities of the two sectors. When both sectors are equally capital-intensive and capital is a better substitute for pollution than is labor, then intuitively we expect the return to capital to rise relative to the wage. If labor and capital are highly complementary, however, then this intuitive result does not hold.

Another surprising result is in the case where both factors are equally substitutable for pollution. In that case, the pollution tax can increase the return to capital even when the polluting sector is more capital-intensive than the other sector, if consumers are less able to substitute among goods than producers of the dirty good are able to substitute among their inputs.

Numerically, it is shown that the elasticities of substitution in production between capital and pollution and between labor and pollution have an important effect on the incidence of a pollution tax. The impact of the uncertainty about substitution elasticities outweighs the impact of the uncertainty about factor intensities.

These results provide evidence that the substitutability of capital, labor, and emissions has very important consequences for environmental policy, and that more work needs to be done in estimating these parameters and analyzing their effects. Not only do these elasticities affect tax incidence, as shown in the main results of this paper, they affect the impact of environmental policy on the environment itself. For alternative parameter values used here, a $10 \%$ increase in the pollution tax rate reduces pollution anywhere from $2 \%$ to $10 \%$. For extreme parameter values, it can lead to more pollution.

Further research could extend in many directions. First, any of the simplifying assumptions of our model could be relaxed to see how results are affected by alternative assumptions such as: imperfect factor mobility, adjustment costs, imperfect competition, non-constant returns to scale, international trade in goods or factors, tax evasion, or uncertainty. In many cases, the results of such extensions can be predicted from the 
literature that followed the original article by Harberger (1962). In a model with perfect international capital mobility, for example, the net return to capital is fixed by world capital markets, and so the pollution tax cannot place a burden on capital - in contrast to the results here for effects on the wage and capital return in a closed economy.

Another direction for further research is to calculate the effects of these price changes on different income groups (or regions, or racial groups). With data on the labor and capital income of each group, our results for $\hat{w}$ and $\hat{r}$ could be used to calculate the effect of a pollution tax on the sources of income for each group. With additional data on the expenditures, our results for $\hat{p}_{Y}$ could be used to calculate the effect on the uses side. Finally, our analytical model could be extended to a computational general equilibrium (CGE) model with more factors, sectors, and groups.

Still, the model in this paper provides the first theoretical analysis of the incidence and distributional effects of environmental policy that allows for fully general forms of substitution among factors and that solves for all general equilibrium effects of the pollution tax. The analytical model is used to derive general propositions that do not depend upon the particular parameter values that must be used in a CGE model. Our model also is used to identify the crucial parameters. In particular, we show how differential substitution between factors can greatly affect the burdens of a pollution tax.

\section{References}

Aidt, Toke S. "Political Internalization of Economic Externalities and Environmental Policy." Journal of Public Economics. Vol. 69, No. 1 (July 1998), 1-16.

Allen, R.G.D. Mathematical Analysis for Economists. St. Martin's, New York (1938).

Antweiler, Werner, Brian R. Copeland, and M. Scott Taylor. "Is Free Trade Good for the Environment?” American Economic Review. Vol. 91, No. 4 (September 2001), 877908.

Babiker, Mustafa H., Gilbert E. Metcalf, and John Reilly. "Tax Distortions and Global Climate Policy." Journal of Environmental Economics and Management. Vol. 46, No. 2 (September 2003), 269-287.

Blundell, Richard, and Steve Bond. "GMM Estimation with Persistent Panel Data: An Application to Production Functions." The Institute for Fiscal Studies Working Paper Series No. 99/4 (1998).

Bovenberg, A. Lans, and Lawrence H. Goulder. "Costs of Environmentally Motivated Taxes in the Presence of Other Taxes: General Equilibrium Analyses." National Tax Journal. Vol. 50, No. 1 (March 1997), 59-87.

and Derek J. Gurney. "Efficiency Costs of Meeting IndustryDistributional Constraints Under Environmental Permits and Taxes." RAND Journal of Economics (forthcoming, 2005).

Carbone, Jared and Kerry Smith. "Average Substitution and Non-Market Effects in Second-Best Policies.” CEnREP Working Paper, July 2004.

Chua, Swee. "Does Tighter Environmental Policy Lead to a Comparative Advantage in Less Polluting Goods?" Oxford Economic Papers. Vol. 55, No. 1 (January 2003), 25-35. 
Claro, Sebastian. "A Cross-Country Estimation of the Elasticity of Substitution Between Labor and Capital in Manufacturing Industries." Cuadernos de Economia. Vol. 40, No. 120 (August 2003), 239-257.

Corbo, P. and V. Meller. "The Substitution of Labor, Skill, and Capital: Its Implications for Trade and Employment." In Trade and Employment in Developing Countries. Anne Krueger, ed., The University of Chicago Press, Chicago (1982).

DeMooij, Ruud A., and A. Lans Bovenberg. "Environmental Taxes, International Capital Mobility and Inefficient Tax Systems: Tax Burden vs. Tax Shifting." International Tax and Public Finance. Vol. 5, No. 1 (February 1998), 7-39.

Fullerton, Don, and Gilbert E. Metcalf. "Environmental Controls, Scarcity Rents, and Pre-existing Distortions.” Journal of Public Economics. Vol. 80, No. 2 (May 2001), 249-267.

and __. "Tax Incidence", in Handbook of Public Economics, A. Auerbach and M. Feldstein, eds., North Holland, Amsterdam (2002).

Griliches, Zvi, and Jacques Mairesse. "Production Functions: The Search for Indentification." In Econometrics and Economic Theory in the Twentieth Century: The Ragnar Frisch Centennial Symposium. Steinar Strom, ed., Cambridge University Press, Cambridge (1998).

Harberger, Arnold C. "The Incidence of the Corporation Income Tax." Journal of Political Economy. Vol. 70, No. 3 (June 1962), 215-240.

Humphrey, David Burras, and J. R. Moroney. "Substitution Among Capital, Labor and Natural Resource Products in American Manufacturing." Journal of Political Economy. Vol. 83, No. 1 (February 1975), 57-82.

Jorgenson, Dale W. and Kevin J. Stiroh. "U.S. Economic Growth at the Industry Level." American Economic Review. Vol. 90, No. 2 (May 2000), 161-167.

Lovell, C. A. Knox. "CES and VES Production Functions in a Cross-Section Context." Journal of Political Economy. Vol. 81, No. 3 (May-June 1973), 705-720.

Mayeres, Inge. "The Distributional Impacts of Policies for the Control of Transport Externalities: An Applied General Equilibrium Model." Fondazione Eni Enrico Mattei Note di Lavoro (1998).

McAusland, Carol. "Voting for Pollution Policy: the Importance of Income Inequality and Openness to Trade." Journal of International Economics. Vol. 61, No. 2 (December 2003), 425-451.

McLure, Charles E. Jr. "General Equilibrium Incidence Analysis: The Harberger Model after Ten Years.” Journal of Public Economics. Vol. 4 (February 1975), 125-161.

Metcalf, Gilbert E. “A Distributional Analysis of Green Tax Reforms." National Tax Journal. Vol. 52, No. 4 (December 1999), 655-681.

Mieszkowski, Peter. "On the Theory of Tax Incidence." Journal of Political Economy. Vol. 75, No. 3 (June 1967), 250-262.

Mieszkowski, Peter. "The Property Tax: An Excise Tax or a Profits Tax?" Journal of Public Economics. Vol. 1, No. 1 (April 1972), 73-96. 
Morgenstern, Richard D. et al. "The Distributional Impacts of Carbon Mitigation Policies.” Resources for the Future, Issue Brief 02-03 (February 2002).

Parry, Ian W.H. "Are Emissions Permits Regressive?" Journal of Environmental Economics and Management. Vol. 47, No. 2 (March 2004), 364-387.

Rapanos, Vassilis T. "A Note on Externalities and Taxation." Canadian Journal of Economics. Vol. 25, No. 1 (February 1992), 226-232.

. "The Effects of Environmental Taxes on Income Distribution." European Journal of Political Economy. Vol. 11, No. 3 (September 1995), 487-501.

Robison, H. David. "Who Pays for Industrial Pollution Abatement?" Review of Economics and Statistics. Vol. 67, No. 4 (November 1985), 702-706.

Wagner, Thomas. "Environmental Policy and the Equilibrium Rate of Unemployment." Journal of Environmental Economics and Management. Vol. 49, No. 1 (January 2005), 132-156.

West, Sarah E. and Roberton C. Williams III. "Estimates from a Consumer Demand System: Implications for the Incidence of Environmental Taxes." Journal of Environmental Economics and Management. Vol. 47, No. 3 (May 2004), 535-558.

\section{Appendix}

Deriving Equations (4) - (7)

Given a set of input prices $p_{K}, p_{L}$, and $p_{Z}$, and output decision $Y$, the solution to the dirty sector's cost-minimization problem consists of three input demand functions:

$$
\begin{aligned}
K_{Y} & =K_{Y}\left(p_{K}, p_{L}, p_{Z} Y\right) \\
L_{Y} & =L_{Y}\left(p_{K}, p_{L}, p_{Z}, Y\right) \\
Z & =Z\left(p_{K}, p_{L}, p_{Z} Y\right)
\end{aligned}
$$

Totally differentiating and dividing through by the appropriate input level yields:

$$
\begin{gathered}
\hat{K}_{Y}=a_{K K} \hat{p}_{K}+a_{K L} \hat{p}_{L}+a_{K Z} \hat{p}_{Z}+\hat{Y}, \\
\hat{L}_{Y}=a_{L K} \hat{p}_{K}+a_{L L} \hat{p}_{L}+a_{L Z} \hat{p}_{Z}+\hat{Y}, \\
\hat{Z}=a_{Z K} \hat{p}_{K}+a_{Z L} \hat{p}_{L}+a_{Z Z} \hat{p}_{Z}+\hat{Y},
\end{gathered}
$$

where $a_{i j}$ is the firm's elasticity of demand for input $i$ with respect to the price of input $j$. As Mieszkowski (1972) notes, this $a_{i j}$ equals $e_{i j} \theta_{Y j}$. Note that $e_{i j}=e_{j i}$, even though $a_{i j} \neq a_{j i}$ in general. Also note that both $e_{i i}$ and $a_{i i}$ must be negative. Allen (1938) also shows that $a_{i K}+a_{i L}+a_{i Z}=0$. Thus at least one of the two cross-price elasticities must be positive. ${ }^{30}$

The three input demand functions are not independent, since the production function gives the relationship between the three inputs and output $Y$. Hence we can use any two of these functions. Again following Mieszkowski, we subtract the third equation

\footnotetext{
${ }^{30}$ Moreover, given symmetry $\left(e_{i j}=e_{j i}\right)$ this result means either that all three cross-price elasticicities $\left(e_{K L}\right.$, $e_{K Z}$, and $e_{L Z}$ ) are positive or that one is negative and the other two are positive.
} 
from each of the first two equations so that the system of the two remaining equations contains all of the Allen elasticities of substitution. When we substitute in the expressions for $a_{i j}$ and the price changes, we get equations (4) and (5) in the text. ${ }^{31}$

Assuming perfect competition, each input to production must be paid a price equal to its marginal product:

$$
\begin{gathered}
p_{X} X_{K}=r\left(1+\tau_{K}\right)=p_{Y} Y_{K}, \\
p_{X} X_{L}=w\left(1+\tau_{L}\right)=p_{Y} Y_{L}, \\
p_{Y} Y_{Z}=p_{Z}=\tau_{Z} .
\end{gathered}
$$

where $X_{K}, X_{L}, Y_{K}, Y_{L}$, and $Y_{Z}$ are the derivatives of the production functions with respect to each input. Perfect competition and constant returns to scale assure that the value of output must equal the sum of factor payments:

$$
\begin{gathered}
p_{X} X=r\left(1+\tau_{K}\right) K_{X}+w\left(1+\tau_{L}\right) L_{X}, \\
p_{Y} Y=r\left(1+\tau_{K}\right) K_{Y}+w\left(1+\tau_{L}\right) L_{Y}+\tau_{Z} Z .
\end{gathered}
$$

Totally differentiate these equations, divide through by sales revenue $\left(p_{X} X\right.$ or $\left.p_{Y} Y\right)$, and rearrange terms to obtain equations (6) and (7) in the text.

General Solution to the System

First, to eliminate $\hat{X}$ and $\hat{Y}$, subtract equation (8) from equation (6) and equation (9) from equation (7):

$$
\begin{gathered}
\hat{p}_{X}=\theta_{X K}\left(\hat{\tau}_{K}+\hat{r}\right)+\theta_{X L}\left(\hat{\tau}_{L}+\hat{w}\right) \\
\hat{p}_{Y}=\theta_{Y K}\left(\hat{\tau}_{K}+\hat{r}\right)+\theta_{Y L}\left(\hat{\tau}_{L}+\hat{w}\right)+\theta_{Y Z} \hat{\tau}_{Z} .
\end{gathered}
$$

Equations (A1-2) tell us how changes in net-of-tax factor prices are passed on to output prices, according to the factor shares in each industry. Substituting equations (8) and (9) into equation (10) yields

$$
\theta_{X K} \hat{K}_{X}+\theta_{X L} \hat{L}_{X}-\theta_{Y K} \hat{K}_{Y}-\theta_{Y L} \hat{L}_{Y}-\theta_{Y Z} \hat{Z}=\sigma_{u}\left(\hat{p}_{Y}+\hat{\tau}_{Y}-\hat{p}_{X}-\hat{\tau}_{X}\right) .
$$

Solving equations (1) and (2) for $\hat{K}_{X}$ and $\hat{L}_{X}$, respectively, and substituting these expressions in to equations (3) and (A3) gives us

$$
\begin{gathered}
-\gamma_{K} \hat{K}_{Y}+\gamma_{L} \hat{L}_{X}=\sigma_{X}\left(\hat{w}+\hat{\tau}_{L}-\hat{r}-\hat{\tau}_{K}\right) \\
-\left(\theta_{X K} \gamma_{K}+\theta_{Y K}\right) \hat{K}_{Y}-\left(\theta_{X L} \gamma_{L}+\theta_{Y L}\right) \hat{L}_{Y}-\theta_{Y Z} \hat{Z}=\sigma_{u}\left(\hat{p}_{Y}+\hat{\tau}_{Y}-\hat{p}_{X}-\hat{\tau}_{X}\right) .
\end{gathered}
$$

Finally, to eliminate $\hat{K}_{Y}$ and $\hat{L}_{Y}$, we use equations (4) and (5) to solve for them and then substitute the resulting expressions into (A4) and (A5). After some rearrangement, these equations become:

$$
\begin{aligned}
& -\sigma_{X}\left(\hat{w}+\hat{\tau}_{L}-\hat{r}-\hat{\tau}_{K}\right)=\left(\gamma_{L}-\gamma_{K}\right) \hat{Z}+\theta_{Y K}\left[\gamma_{L}\left(e_{L K}-e_{Z K}\right)-\gamma_{K}\left(e_{K K}-e_{Z K}\right)\right]\left(\hat{r}+\hat{\tau}_{K}\right) \\
& +\theta_{Y L}\left[\gamma_{L}\left(e_{L L}-e_{Z L}\right)-\gamma_{K}\left(e_{K L}-e_{Z L}\right)\right]\left(\hat{w}+\hat{\tau}_{L}\right)+\theta_{Y Z}\left[\gamma_{L}\left(e_{L Z}-e_{Z Z}\right)-\gamma_{K}\left(e_{K Z}-e_{Z Z}\right)\right] \hat{\tau}_{Z}
\end{aligned}
$$

\footnotetext{
${ }^{31}$ DeMooij and Bovenberg (1998) derive analogous expressions with a fixed input factor or price.
} 


$$
\begin{aligned}
& -\sigma_{u}\left(\hat{p}_{Y}+\hat{\tau}_{Y}-\hat{p}_{X}-\hat{\tau}_{X}\right)=C \hat{Z}+\theta_{Y K}\left[\beta_{K}\left(e_{K K}-e_{Z K}\right)+\beta_{L}\left(e_{L K}-e_{Z K}\right)\right]\left(\hat{r}+\hat{\tau}_{K}\right) \\
& +\theta_{Y L}\left[\beta_{K}\left(e_{K L}-e_{Z L}\right)+\beta_{L}\left(e_{L L}-e_{Z L}\right)\right]\left(\hat{w}+\hat{\tau}_{L}\right)+\theta_{Y Z}\left[\beta_{K}\left(e_{K Z}-e_{Z Z}\right)+\beta_{L}\left(e_{L Z}-e_{Z Z}\right)\right] \hat{\tau}_{Z}
\end{aligned}
$$

At this point we reduce the generality of the system, allowing for a more interpretable solution. Let $\hat{\tau}_{X}=\hat{\tau}_{Y}=\hat{\tau}_{K}=\hat{\tau}_{L}=0$, so that the only tax changing is the pollution tax. Also, set good $X$ as the numeraire, so that $\hat{p}_{X}=0$. Then, plugging equation (A2) into (A7) to eliminate $\hat{p}_{Y}$ yields, after some rearrangement:

$$
\begin{gathered}
C \hat{Z}=-\theta_{Y K}\left[\beta_{K}\left(e_{K K}-e_{Z K}\right)+\beta_{L}\left(e_{L K}-e_{Z K}\right)+\sigma_{u}\right] \hat{r} \\
-\theta_{Y L}\left[\beta_{K}\left(e_{K L}-e_{Z L}\right)+\beta_{L}\left(e_{L L}-e_{Z L}\right)+\sigma_{u}\right] \hat{w} \\
-\theta_{Y Z}\left[\beta_{K}\left(e_{K Z}-e_{Z Z}\right)+\beta_{L}\left(e_{L Z}-e_{Z Z}\right)+\sigma_{u}\right] \hat{\tau}_{Z}
\end{gathered}
$$

Solve (A3) and (A8) for $\hat{Z}$, equate, and rearrange, to get:

$$
\begin{aligned}
& {\left[\theta_{Y K}\left(-A\left(e_{K K}-e_{Z K}\right)+B\left(e_{L K}-e_{Z K}\right)+\left(\gamma_{K}-\gamma_{L}\right) \sigma_{u}\right)+C \sigma_{X}\right] \hat{r}} \\
& +\left[\theta_{Y L}\left(-A\left(e_{K L}-e_{Z L}\right)+B\left(e_{L L}-e_{Z L}\right)+\left(\gamma_{K}-\gamma_{L}\right) \sigma_{u}\right)-C \sigma_{X}\right] \hat{w} \\
& =\theta_{Y Z}\left[-A\left(e_{Z Z}-e_{K Z}\right)+B\left(e_{Z Z}-e_{L Z}\right)+\left(\gamma_{L}-\gamma_{K}\right) \sigma_{u}\right] \hat{\tau}_{Z}
\end{aligned}
$$

Now equations (A1) and (A9) are two equations in only two unknowns, $\hat{r}$ and $\hat{w}$. Use (A1) to solve for $\hat{w}$ in terms of $\hat{r}$, substitute into (A9), and simplify, to reach equation (11b) in the text. Substitute this back into previous equations to obtain the equations for $\hat{r}, \hat{Z}$, and $\hat{p}_{Y}(11 \mathrm{a}, \mathrm{c}, \mathrm{d})$. 